\title{
Alternatif Pohon Buah untuk Penghijauan Permukiman Perkotaan Berdasarkan Pendugaan Tingkat Keindahan dan Pendapat Masyarakat di Kelurahan Rejowinangun, Yogyakarta
}

\section{Study on Fruit Trees for Street Greenary in Urban Settlement Based on Aesthetics Level and Community Response in Rejowinangun District, Yogyakarta}

\author{
Cut Annisa Nabila'), Siti Nurul Rofiqo Irwan $^{2 *}$, Budiastuti Kurniasih²), Erlina Ambarwati2) \\ 1) Program Studi Agronomi, Fakultas Pertanian, Universitas Gadjah Mada \\ 2) Departemen Budidaya Pertanian, Fakultas Pertanian, Universitas Gadjah Mada \\ *) Penulis untuk korespodensi E-mail: rofiqoirwan@ugm.ac.id
}

\begin{abstract}
The interest of the Rejowinangun community to planting fruit trees as urban street greenery, as part of the development of productive landscapes, is quite high. The research aims to recognize the community response on the fruit trees for street greenery of urban settlement and to measure the aesthetic level of the fruit trees. The research was conducted by survey using stratified purposive sampling method in Rejowinangun Kotagede Yogyakarta city and analized by Scenic Beauty Estimation (SBE). The results showed that the public agreed about planting fruit trees for urban street greenery by considering the technical planting of trees. The people recognized fruit trees covered $11.11 \%$ at the secondary road, $21.48 \%$ at the tertiary road, and $20 \%$ at the quarter road from people. Level of aesthetics (SBE value) for several fruit trees as street greenery was guava tree $(67,61)$, kepel tree $(67,22)$, and guava var. dersono tree $(61,13)$.
\end{abstract}

Keywords: street greenery, urban settlement, Scenic Beauty Estimation (SBE), fruit trees, productive landscape

\section{INTISARI}

Minat masyarakat Permukiman Rejowinangun Yogyakarta terhadap penanaman pohon buah untuk alternatif tanaman penghijauan, sebagai bagian dari pengembangan lanskap produktif, cukup tinggi. Penelitian bertujuan mengetahui pendapat masyarakat mengenai penghijauan permukiman perkotaan dengan pohon buah serta mengetahui tingkat keindahan alternatif pohon buah. Metode penelitian dilakukan dengan metode survei pengambilan data secara stratified purposive sampling dan analisis Scenic Beauty Estimation (SBE). Penelitian dilaksanakan di Kelurahan Rejowinangun Yogyakarta. Hasil penelitian menunjukkan, sebagian besar masyarakat setuju terhadap pelaksanaan penghijauan dengan pohon buah dengan memperhatikan teknis penanaman pohon. Pengetahuan masyarakat Rejowinangun terhadap buah lokal Yogyakarta di sekitar jalan sekunder sebesar $11,11 \%$, jalan tersier sebesar $21,48 \%$, dan jalan kuarter sebesar $20 \%$. Alternatif pohon buah untuk penghijauan jalan dengan nilai SBE tertinggi yaitu jambu air 
(Eugenia aquea; 67,61), kepel (Stelechocarpus burahol; 67,22), dan jambu dersono (Syzygium malaccense; 61,13).

Kata kunci : penghijauan kota, permukiman perkotaan, Scenic Beauty Estimate (SBE), pohon buah, lanskap produktif

\section{PENDAHULUAN}

Provinsi Daerah Istimewa Yogyakarta mengalami peningkatan suhu udara sekitar $0,04^{\circ} \mathrm{C}$ per tahun sejak tahun 2007 (Hasanudin, 2016). Peningkatan suhu udara dipengaruhi oleh kehidupan perkotaan. Sebagai salah satu kota di provinsi DIY, kota Yogyakarta memiliki angka kepadatan penduduk yang cukup tinggi yaitu 15,253 jiwa/km² (Pemerintah Kota Yogyakarta, 2014). Rejowinangun merupakan salah satu kelurahan di Kota Yogyakarta yang dikenal dengan Kampung Wisata Agro Edukasi. Pengembangan lanskap produktif pada permukiman Rejowinangun sangat diperlukan untuk meningkatkan kualitas lingkungan serta kenyamanan peduduknya.

Lanskap produktif perkotaan merupakan ruang hijau perkotaan yang dikelola sedemikian rupa agar fungsi ekonomi, sosiokultur dan lingkungan/ekologi dapat terpenuhi. Perpaduan keberlanjutan lanskap perkotaan dengan pertanian perkotaan dapat mendukung ketahanan pangan masyarakat perkotaan. Sehingga, diharapkan mampu menyediakan nutrisi yang lebih sehat dan terjangkau bagi masyarakat (Viljoen, et al., 2005). Salah satu bentuk pengembangan lanskap produktif pada permukiman perkotaan yaitu lanskap jalan. Carpenter et al. (1975) menyatakan, pada perencanaan lanskap jalan diperlukan pertimbangan nilai fungsi keamanan, kenyamanan, ekonomi, dan estetika.

Pengelolaan lanskap perkotaan dipengaruhi oleh status ekonomi, pendidikan, etnis, serta gaya hidup penduduknya. Permukiman penduduk perkotaan di Amerika Serikat dengan status ekonomi tinggi, lebih banyak ditemukan vegetasi yang terpelihara dengan baik, daripada permukiman penduduk perkotaan dengan status ekonomi rendah. (Escobedo et al.; Kirkpatrick et al.; Conway dan Hackworth cit. Boone, 2010).Sebuah studi mengenai hutan kota di 60 kota di Indiana Tengahmenunjukkan bahwa, adanya hutan kota secara signifikan berkorelasi positif dengan persentase penduduk dengan latar pendidikansarjana (Heynen dan Lindsey cit. Boone et al., 2010).

Penelitian mengenai karakteristik vegetasi di Toronto menunjukkan bahwa, pohon peneduh lebih banyak ditemukan di rumah penduduk berkebangsaan Inggris, dibandingkan 
dengan rumah penduduk berkebangsaan keturunan Cina (Fraser dan Kenney cit. Boone et al., 2010). Gaya hidup seseorang berhubungan dengan adanya preferensi penataan penanaman vegetasi di sekitar tempat tinggalnya (Boone et al., 2010).

Pohon buah merupakan salah satu jenis tanaman yang dapat di gunakan sebagai tanaman lanskap jalan. Sea Apple (Syzygium grande) merupakan salah satu pohon sejenis jambu air yang di tanam di sepanjang tepi jalan negara Singapura sejak awal tahun 1900an (National Park, 2014). Apel, mangga, alpukat, plum, dan kelapa termasuk dalam jenis pohon buah dalam program penghijauan perkotaan di Kenya. Namun, pohon-pohon tersebut ditanam di pekarangan rumah, taman kota, serta taman kompleks lembaga aparat negara (Kiboi et al., 2014).

Berdasarkan hasil penelitian Nabila et al., 2017, alternatif pohon buah untuk penghijauan permukiman Rejowinangun berdasarkan kesesuaian lahan yaitu asam jawa, belimbing buah, belimbing wuluh, buah mentega, gandaria, jambu air, jambu biji, jambu dersono, jambu mete, kepel, kersen lengkeng, manggis, rambutan, sawo manila, sawo duren, dan sawo kecik. Diketahui minat masyarakat permukiman Rejowinangun Yogyakarta terhadap penanaman pohon buah untuk penghijauan cukup tinggi. Penelitian ini diharappkan dapat mengetahui alternatif pohon buah untuk penghijauan permukiman perkotaan berdasarkan persepsi masyarakat dan estetika, sehingga dapat meningkatkan kenyamanan aktivitas perkotaan.

\section{BAHAN DAN METODE}

Pengambulan data dilakukan pada bulan Mei-Juni 2017, di Kampung Pilahan RT 40/RW 12 pada lima rukun tetangga (RT) yaitu RT 41-44/RW 13, Kelurahan Rejowinangun, Kecamatan Kotagede, Yogyakarta. Penelitian dilakukan dengan metode survei, pengambilan data menggunakan metode stratified purposive sampling dan analisis pendugaan keindahan/ Scenic Beauty Estimate (SBE). Dasar pemilihan sample berdasar masyarakat yang berada pada tiga klasifikasi jalan lingkungan yaitu jalan sekunder, jalan tersier, dan jalan kuarter di setiap RT, pada lima RT, sehinnga terdapat 15 lokasi sampel. Adanya perbedaan klasifikasi jalan ini ditujukan untuk perbedaan jenis pohon buah yang akan ditanam di permukiman. Jumlah total responden 51 orang, terdiri dari ibu-ibu, dengan besarnya sampel (responden) per lokasi/stratum dihitung menggunakan rumus berikut (Nazir, 2011) : 
Cut Annisa Nabila et al., / Vegetalika. 2018. 7(1): 13-25

keterangan :

$$
n_{i}=f_{i} \cdot n
$$

$\mathrm{f}_{\mathrm{i}}=$ sampling fraction stratum $\mathrm{i} \quad\left(f_{i}=\frac{N_{i}}{N}\right)$ dimana $\mathrm{N}_{\mathrm{i}}=$ populasi pada startum ke-i, dan $\mathrm{N}=$ populasi total

$\mathrm{n}=$ jumlah sampel yang akan diambil (50)

Alat yang digunakan dalam penelitian meliputi alat peraga (gambar alternatif beberapa pohon buah), meteran, kuesioner, kamera digital, dan komputer. Bahan yang digunakan berupareferensi buku pohon penghijauan dan alat tulis.

Data-data yang dikumpulkan berupa data sekunder dan data primer. Data sekunder berupa referensi hasil penelitian Nabilaet al. (2017) menjadi acuan pengambilan data primer di lapangan. Data primer meliputi data fisik (lebar jalan dan kondisi lingkungan) serta data sosial (pendapat masyarakat terhadap penghijauan dengan pohon buah di permukiman perkotaan serta tingkat keindahan alternatif pohon buah). Komponenkomponen pohon sebagai variabel penilaian tingkat keindahan yaitu bentuk tajuk, bentuk batang, corak batang, bentuk daun, warna daun, bentuk bunga, warna bunga, bentuk buah, tekstur pohon, serta kerindangan/bayangan. Kriteria skala penilaian pendugaan tingkat keindahan yang digunakan adalah : 1. sangat tidak indah, 2.tidak indah, 3. kurang indah, 4. biasa saja, 5 . sedikit indah, 6 . indah, dan 7 sangat indah.

Hasil kuesioner pendapat masyarakat terhadap penghijauan permukiman perkotaan dengan pohon buah di analisis dengan Kruskal Wallis-Test $\alpha 5 \%$ menggunakan software $R$ versi 3.3.2. Pendugaan tingkat keindahan terhadap alternatif pohon buah dianalisis dengan metode Scenic Beauty Estimate (SBE) menggunakan nilai Z. Nilai Z merupakan nilai yang diberikan oleh responden terhadap gambar beberapa altenatif pohon buah. Pada setiap gambar, dihitung frekuensi (f), frekuensi kumulatif (cf), peluang kumulatif $(\mathrm{cp})$, nilai $\mathrm{z}$, dan nilai z rata-rata. Khusus untuk nilai $\mathrm{cp}=1.00$ digunakan rumus perhitungan $c p=1-1 /(2 n)$ dan untuk nilai $c p=0$ ( $z=$ tak terhingga) digunakan rumus $c p=1 /(2 n)$. Nilai SBE dihitung dengan rumus sebagai berikut (Daniel dan Boster, 1976) :

$$
S B E_{x}=\left(Z_{L S-X}-Z_{L S-P}\right) \times 100
$$

Keterangan : $\mathrm{SBE}_{\mathrm{x}}$ : Nilai pendugaan keindahan pemandangan ke $-\mathrm{x}$; $\mathrm{Z}_{\mathrm{LS}-\mathrm{x}}$ : Rata-rata nilai $z$ untuk gambar atau foto ke - x; ZLS-P : Rata-rata nilai $z$ untuk gambar atau foto pembanding (obyek dengan nilai $Z$ rata-rata terkecil). 
Cut Annisa Nabila et al., / Vegetalika. 2018. 7(1): 13-25

\section{HASIL DAN PEMBAHASAN}

Kondisi jalan sekunder yang lebih lebar dibandingkan dengan jalan tersier dan kuarter, memudahkan akses kendaraan yang melewati jalan sekunder. Kondisi permukiman yang berada di sekitar bangunan TK, SD, dan kantor kelurahan, menyebabkan diperlukannya alternatif penanaman pohon buah dengan kemampuan reduktor polutan pada jalan sekunder. Responden pada penelitian ini terdiri dari ibu-ibu dengan beragam karakteristik usia, pendidikan, serta pekerjaan.

Tabel 1. Respon masyarakat Rejowinangun terhadap penghijauan pohon buah berdasarkan klasifikasi jalan

\begin{tabular}{lccc}
\hline \multicolumn{1}{c}{$\begin{array}{c}\text { Respon } \\
\text { Masyarakat }\end{array}$} & \multicolumn{3}{c}{ Klasifikasi Jalan } \\
\cline { 2 - 4 } & $\begin{array}{c}\text { Jalan } \\
\text { Sekunder }\end{array}$ & $\begin{array}{c}\text { Jalan } \\
\text { Tersier }\end{array}$ & $\begin{array}{c}\text { Jalan } \\
\text { Kuarter }\end{array}$ \\
\hline Pohon Buah untuk Penghijauan & $\mathrm{S}$ & $\mathrm{S}$ & $\mathrm{S}$ \\
Partisipasi dalam pemeliharaan & $\mathrm{S}$ & $\mathrm{S}$ & $\mathrm{S}$ \\
Resiko serangan OPT & TS & $\mathrm{S}$ & TS \\
Resiko kerontokan sampah pohon & TS & TS & TS \\
Potensi kerusakan konstruksi jalan & TS & TS & S \\
Potensi pohon roboh saat angin kencang & TS & TS & TS \\
\hline
\end{tabular}

Keterangan : Huruf yang ditampilkan adalah konversi dari nilai median. Kriteria skor penilaian pada setiap indikator pengujian: TS (Tidak Setuju) dan S(Setuju).

Berdasarkan Tabel 1, terlihat bahwa sebagian besar masyarakat Rejowinangun setuju dilakukan penghijauan dengan pohon buah. Hal tersebut, diketahui dari prosentase responden yang setuju di sekitar jalan sekunder (77,78\%), jalan tersier (89,29\%), dan jalan kuarter (100\%). Harapan masyarakat dengan adanya penanaman pohon buah tersebut, lingkungan menjadi lebih sejuk, meningkatkan keindahan lingkungan, mempercepat pembuangan air ketika hujan turun sehingga tidak ada genangan, mengurangi polusi udara, serta menghasilkan buah yang bisa dikonsumsi masyarakat ataupun menjadi salah satu sumber tambahan pendapatan masyarakat dari penjualan hasil panenannya. Namun, terkendala dengan lahan yang sempit, dan kondisijalan yang sebagian besar sudah dikonblok serta diaspal.

Adanya penghijauan dengan pohon buah membutuhkan upaya pemeliharaan dari masyarakat setempat. Kondisi jalan sekunder yang merupakan jalan lebih umum untuk dilewatin kendaraan, menjadikan jalan tersebut membutuhkan pemeliharaan lebih dibandingkan dengan jalan tersier dan kuarter. Masyarakat usia lanjut ( $>55$ tahun) dan 
kesibukan pekerjaan responden di jalan sekunder tetap menjadikan masyarakat peduli dalam melakukan pemeliharaan pohon penghijauan.

Sebagian besar responden di berbagai klasifikasi jalan bersedia berpartisipasi aktif dalam kegiatan pemeliharaan pohon buah, yakni jalan sekunder $(88,89 \%)$, jalan tersier $(89,29 \%)$, dan jalan kuarter (100\%). Masyarakat yang tidak bersedia peran aktif dalam melakukan pemeliharaan menganggap perawatan pohon buah itu sulit, serta perlu mengeluarkan biaya yang relatif mahal. Sedangkan, masyarakat yang setuju adanya penghijauan dengan pohon buah, mengharapkan agar nantinya ketua RT aktif melakukan pengontrolan dalam hal pemeliharaannya, sehingga tidak ditemukan masalah seperti dahan pohon yang menggangu mobilitas kendaraan di sekitar jalan.

Salah satu bentuk pemeliharaan yang perlu diperhatikan yaitu pengendalian OPT. Jenis OPT yang paling ditakuti oleh masyarakat Rejowinangun adalah ulat dan semut rangrang. Prosentase responden yang tidak khawatir terhadap resiko serangan OPT pada tanaman pohon buah di sekitar jalan sekunder (72,22\%) dan jalan kuarter (60\%), lebih tinggi dibandingkan jalan tersier (35,71\%). Hal tersebut, didukung dengan kepahaman masyarakat dalam tindakan penanganan serangan ringan OPTnya (pengalaman), seperti dengan penyemprotan air deterjen serta pembuangan hama secara manual.

Setiap jenis pohon memiliki kelebihan serta kekurangan masing-masing, salah satunya yaitu sampah pohon. Daun, bunga, ataupun buah pohon memiliki tingkat kerontokan yang berbeda-beda. Sebagian besar masyarakat menyatakan bahwa sampah pohon bukan merupakan sebuah permasalahan, yakni jalan sekunder $(66,67 \%)$, jalan tersier (82,14\%), dan jalan kuarter (100\%). Hal tersebut dikarenakan, resiko membersihkan sampah pohon dinilai lebih kecil, bila dibandingkan dengan kebermanfaatan pohon buah.

Kekurangan pohon lainnya, yaitu kerusakan konstruksi jalan akibat permasalahan sistem perakaran pohon. Kondisi jalan yang sempit dan penanaman jenis pohon dengan sistem perakaran pohon yang dangkal sangat beresiko merusak konstruksi jalan. Sebagian besar masyarakat di sekitar jalan kuarter (60\%) lebih takut terhadap resiko tersebut, bila dibandingkan dengan masyarakat di sekitar jalan sekunder $(27,78 \%)$ dan jalan tersier $(35,71 \%)$. Masyarakat yang tidak takut dengan adanya potensi kerusakan konstruksi jalan berpendapat, bahwa potensi tersebut dapat diatasi dengan pengaturan teknis penanamannya. Resiko penanaman pohon lainnya, yakni permasalahan pohon roboh saat angin kencang. Kerobohan pohon dapat menyebabkan kerusakan rumah, tiang listrik, 
Cut Annisa Nabila et al., / Vegetalika. 2018. 7(1): 13-25

ataupun bangunan lainnya. Sebagian besar masyarakat yang berada di berbagai klasifikasi jalan menyatakan bahwa resiko tersebut bukan merupakan permasalahan, dengan persentase masyarakat yang tidak mempermasalahkan yakni jalan sekunder $55,56 \%$, jalan tersier $64,29 \%$, dan jalan kuarter 60\%). Potensi tumbang pohon dapat diantisipasi dengan pemilihan jenis pohon dengan perakaran yang kuat, serta dilakukan pemangkasan rutin jika tajuk pohonnya sudah dinilai terlalu rimbun dan tidak aman untuk keselamatan.

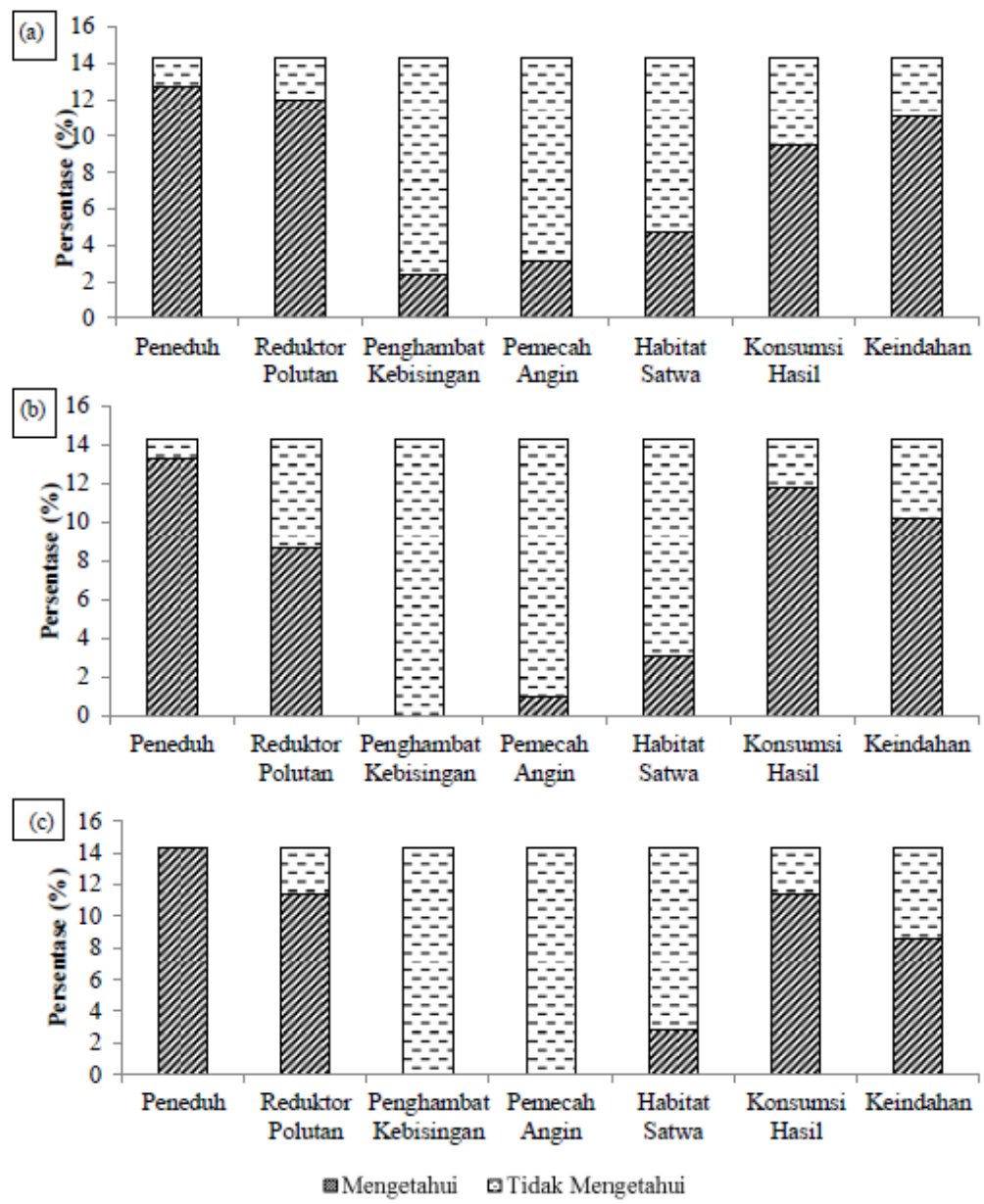

Gambar 1. Pemahaman mayarakat Rejowinangun terhadap potensi pohon buah untuk penghijauan. (a) Jalan sekunder, (b) Jalan tersier, dan (c) Jalan kuarter

Pohon penghijauan memiliki potensi sebagai peneduh, sebagai reduktor polutan, penghambat kebisingan, pemecah angin, habitat satwa (seperti capung, burung, dan sebagainya), dikonsumsi buahnya, serta estetika/keindahan. Gambar 1, menunjukkan sebagian besar masyarakat Rejowinangun mengetahui potensi pohon penghijauan sebagai 
peneduh, sebagai reduktor polutan, habitat satwa, dikonsumsi buahnya, serta estetika/keindahan. Sedangkan potensi pohon buah sebagai penghambat kebisingan dan pemecah angin sebagian besar belum diketahui masyarakat. Hal tersebut terlihat dari prosentase pengetahuan masyarakat terhadap potensi pohon sebagai penghambat kebisingan (jalan sekunder 2,38\%, jalan tersier dan jalan kuarter masing-masing $0 \%$ ) dan pemecah angin (jalan sekunder 3,17\%, jalan tersier $1,02 \%$ dan jalan kuarter $0 \%$ ) relatif kecil. Secara umum, respon masyarakat Rejowinangun yang tinggal di berbagai klasifikasi jalan tidak terlihat adanya perbedaan terhadap potensi pohon penghijauan. Hal demikian, dikarenakan walaupun latar belakang pendidikan responden berbeda-beda pada tiap klasfikasi jalannya. Jurusan Perguruan Tinggi yang dimiliki responden tidak seluruhnya berhubungan dengan lingkungan.

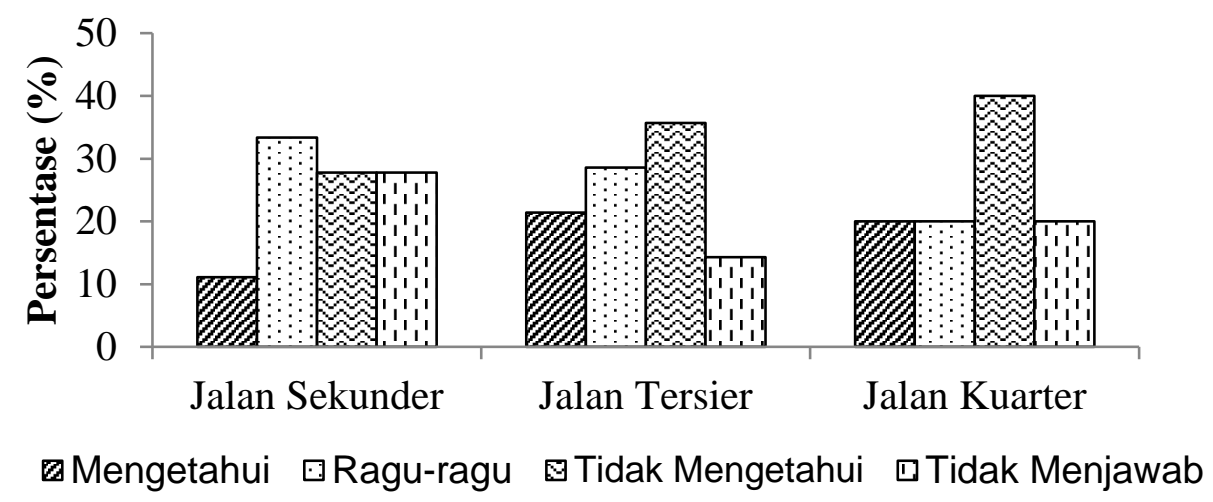

Gambar 2. Pengetahuan mayarakat Rejowinangun terhadap buah lokal.

Adapun jenis pohon buah lokal yang menjadi identitas Yogyakarta yaitu belimbing wuluh (Averrhoa bilimbi), jambu dersono (Eugenia malaccensis), kelapa gading (Cocus nucifera), kepel (Stelechocarpus burahol), kweni (Mangifera odorata), pakel (Mangifera foetida), serta sawo kecik (Manilkara kauki) (Sunjata et al., 1993). Namun, tidak semua masyarakat mengetahui jenis pohon buah local Yogyakarta. Pada Gambar 2, terlihat bahwa pengetahuan masyarakat Rejowinangun terhadap buah lokal Yogyakarta masih tergolong rendah. Hal tersebut, terlihat dari nilai prosentase masyarakat yang mengetahui buah lokal Yogyakarta relatif rendah, baik masyarakat yang tinggal di sekitar jalan sekunder, tersier, maupun kuarter yakni $<25 \%$. Hal tersebut dikarenakan, sebagian masyarakat Rejowinangun bukanlah masyarakat asli Yogyakarta. 
Cut Annisa Nabila et al., / Vegetalika. 2018. 7(1): 13-25

Berdasarkan hasil perhitungan rerata berbagai komponen pohon dari masingmasing pohon buah, di dapatkan pendugaan keindahan dengan nilai SBE (Scenic Beauty Estimate) masing-masing alternatif pohon buah yang dapat dilihat pada Gambar 3.

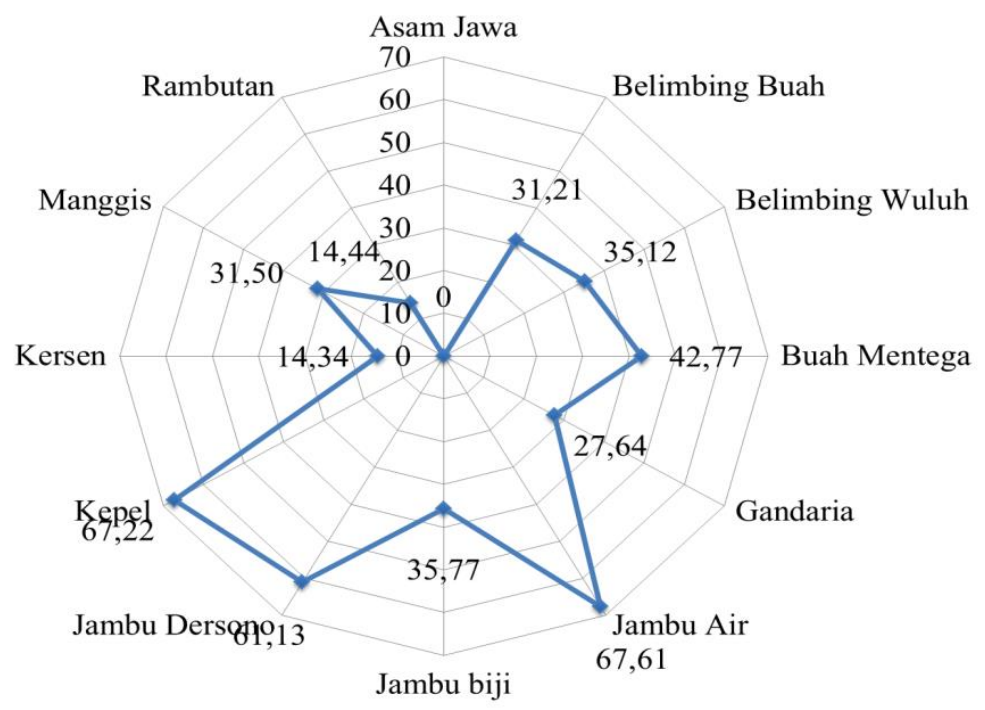

Gambar 3. Nilai pendugaan keindahan/Scenic Beauty Estimation (SBE) pada berbagai alternatif pohon buah

Gambar 3, menunjukkan nilai estetika pohon buah yang tertinggi hingga terendah berdasarkan nilai SBE. Semakin mendekati titik pusatnya pada grafik, estetika/kualitas keindahan akan semakin rendah, pohon buah akan memiliki nilai SBE yang semakin rendah. Sebagian besar responden, menilai pada skala 5 dan 6 (interval 1-7) yaitu sedikit indah dan indah. Pohon buah dengan nilai SBE tinggi dipresentasikan oleh jambu air (Eugenia aquea) $(67,61)$, kepel (Stelechocarpus burahol) $(67,22)$, dan jambu dersono (Eugenia malaccensis) (61,13), sedangkan nilai SBE terendah direpresentasikan oleh asam jawa (Tamarindus indica) (0).

Lanskap dengan nilai pendugaan estetika tertinggi merupakan lanskap yang paling disukai atau indah (Daniel dan Boster, 1976). Menurut responden, asam jawa (Tamarindus indica) kurang diminati karena memiliki keragaan pohon yang menyerupai pohon beringin yang terkesan mistis. Pohon jambu air (Eugenia aquea) $(67,61)$ dan jambu dersono (Eugenia malaccensis) diminati masyarakat, karena memiliki kerindangan tajuk yang indah, warna dan bentuk bunga yang menarik, warna buah yang bervariasi, rasa buah yang disukai, serta memililiki berbagai macam khasiat untuk kesehatan. Pohon kepel 
(Stelechocarpus burahol) diminati masyarakat, karena posisi buah yang menggantung di batang pohon terkesan unik.

Alternatif jenis pohon buah yang digunakan berkemampuan mereduksi polutan, karenakan jalan sekunder merupakan akses kendaraan menuju TK, SD, dan kantor Kelurahan. Jenis pohon berkemampuan mereduksi polutan ditandai dengan permukaan daun berambut, bentuk pertumbuhan konifer dan evergreen, serta terkadang memiliki aroma harum (Grey dan Deneke cit. Arifin, 2008). Pada jalan tersier dan jalan kuarter dengan lebar jalan sekitar 3,5-4 m, dapat dilakukan penanaman pohon buah menggunakan pola penanaman zigzag. Berikut rekomendasi jalur tanaman pada jalan permukiman baik jalan tersier maupun kuarter dapat dilihat pada Gambar 4 dan 5.

(a)

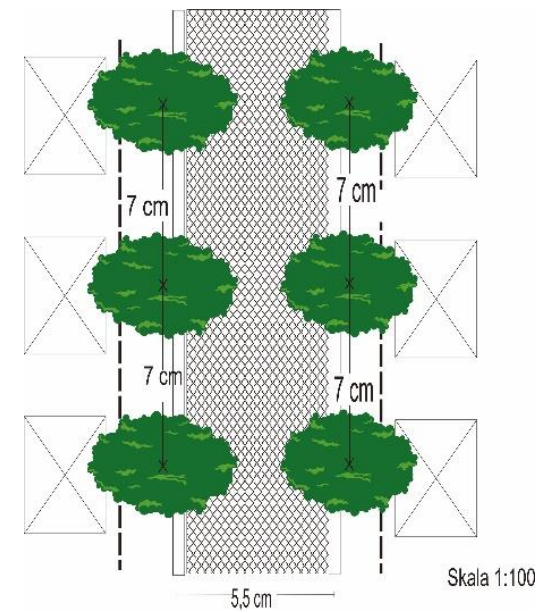

(b)

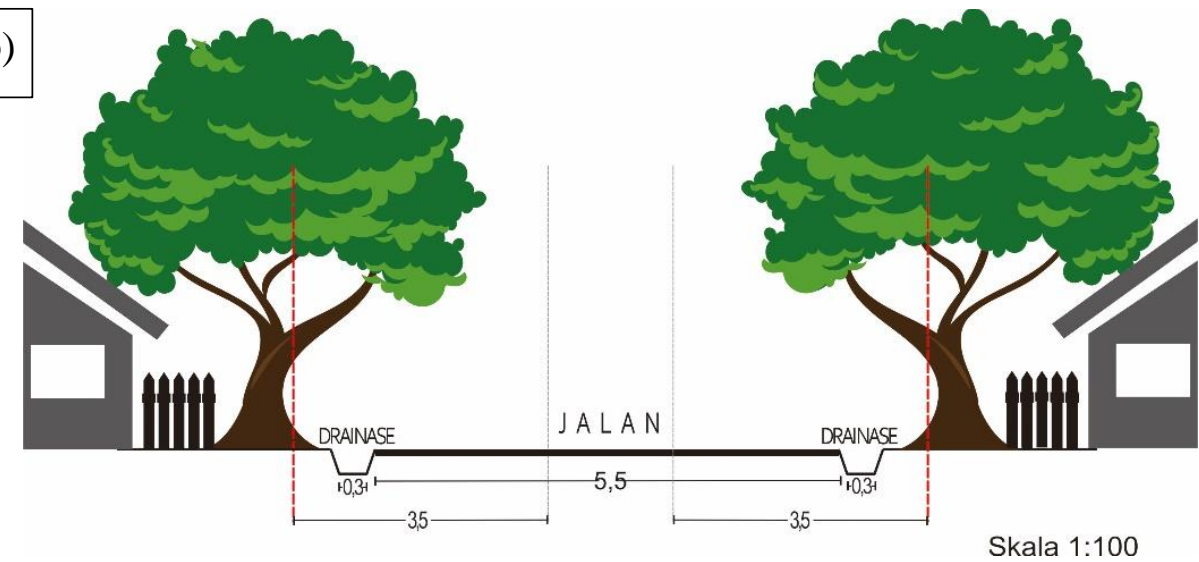

Gambar 4. Rekomendasi jalur tanaman pada jalan permukiman perkotaan sekunder. (a) tampak atas dan (b) tampak depan 


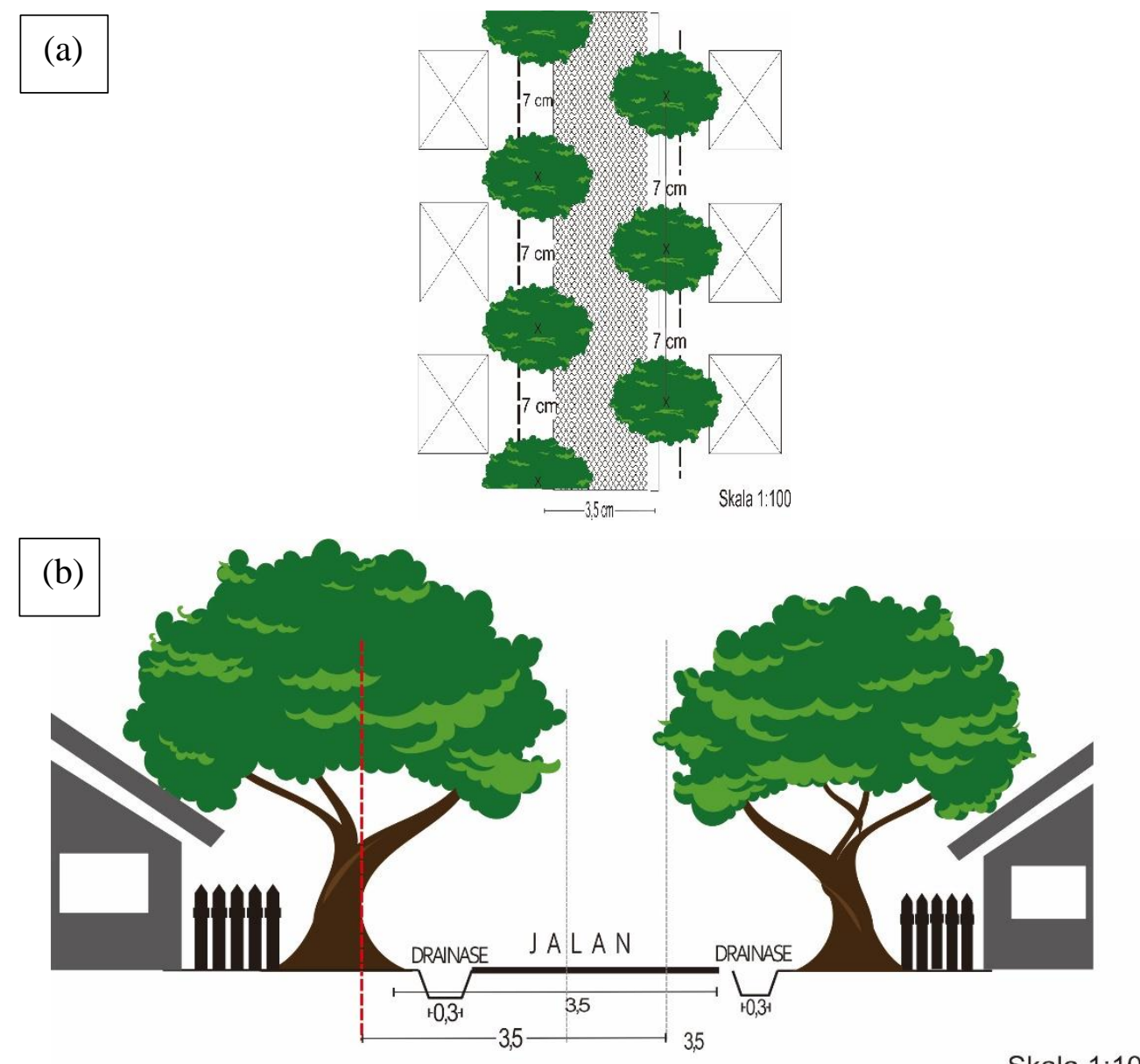

Gambar 5. Rekomendasi jalur tanaman pada jalan permukiman perkotaan tersier dan jalan permukiman perkotaan kuarter. (a) tampak atas dan (b) tampak depan

Kedua jenis jalan tersebut relatif jarang dilalui oleh kendaraan bermobil, dan relatif sedikit dilewati kendaraan bermotor. Oleh karena itu, jenis pohon yang ditanam tidak harus menghendaki jenis pohon berkemampuan sebagai reduktor polutan. Alternatif pohon buah yang dapat ditanam di pinggir jalan sekunder diantaranya belimbing buah (Averrhoa carambola), belimbing wuluh (Averrhoa bilimbi), bisbul (Diospyros philippensis), jambu biji (Psidium guajava L), kepel (Stelechocarpus burahol), kersen (Muntingia calabura), manggis (Garcinia mangostana), serta rambutan (Nephelium lappaceum). Adapun alternatif pohon buah yang dapat ditanam dipinggir jalan jalan tersier serta jalan kuarter yaitu gandaria 
Cut Annisa Nabila et al., / Vegetalika. 2018. 7(1): 13-25

(Bovea macrophylla), jambu air (Eugenia aquea), jambu dersono (Syzygium malaccense).

Selain itu, pada jalan tersier serta jalan kuarter juga bisa ditanami dengan alternatif pohon buah yang bisa ditanami di jalan sekunder.

\section{KESIMPULAN}

1. Sebagian besar masyarakat Rejowinangun, lebih dari $77 \%$, setuju t pohon buah untuk penghijauan jalan lingkungan di permukiman Rejowinangun.

2. Alternatif pohon buah untuk penghijauan jalan berdasarkan nilai Scenic Beauty Estimation (SBE) tertinggi yaitu jambu air (Eugenia aquea) (67,61), kepel (Stelechocarpusburahol) $(67,22)$, dan jambu dersono (Syzygium malaccense) $(61,13)$.

\section{DAFTAR PUSTAKA}

Boone, C.G., M. L. Cadenasso, J. M. Grove, K. Schwarz, dan G. L. Buckley. 2010. Landscape, vegetation characteristics, and group identity in an urban and suburban watershed: why the 60s matter. Urban Ecosyst 13:: 256.

Carpenter, P.L., T.D. Walker, dan F.O. Lanphear. 1975. Plants in the Landscape. W.H. Freeman and Company, San Francisco. 476p.

Daniel C, dan Boster RS. 1976. Measuring Landscape Aesthetic: The Scenic Beauty Estimation Method. New Jersey: USDA. 66hal.

Hall, P., K. Lofgren, dan G. Peters. 2016. Greening the Street-Level Procurer: Challenges in the Strongly Decentralized Swedish System. Journal of Consum Policy 39: 467.

Hasanudin, U. 2016. BLH kota Jogja giatkan penghijauan. Harian Jogja. <http://m.harianjogja.com/baca/2016/03/18/pemanasan-global-blh-kota-jogjagiatkan-penghijauan-701983>. Diakses 29 Desember 2016.

Kiboi, S., K. Fujiwara, and Patrick Mutiso. 2014. Sustainable management of urban gree environments: Challenges and Opportunities. In: Sustainable Living with Environmental Risks. Springer Tokyo Heidelberg New York Dordrecht London, p: 232 dan 239

Nabila, C.A., S.N.R. Irwan, B. Kurniasih. 2017. Kajian alternatif pohon buah untuk penghijauan permukiman perkotaan di kawasan Rejowinangun, Yogyakarta. Prosiding Seminar Nasional Hasil Penelitian Pertanian VII. Fakultas Pertanian UGM.

National Park. 2014. Know 10 Trees. <https://www.nparks.gov.sg/activities/family-time-with nature/recommended-activities/know-10-trees>. Diakses 10 Juli 2017. 
Cut Annisa Nabila et al., / Vegetalika. 2018. 7(1): 13-25

Nazir, Moh. 2011. Metode Penelitian. Ghalia Indonesia, Bogor.

Pemerintah Kota Yogyakarta. 2014. Laporan status lingkungan hidup daerah Kota Yogyakarta tahun 2014. <http://blh.jogjaprov.go.id/po-content/uploads/BukuLaporan-SLHD-Kota-Yogyakarta-2014.pdf>. Diakses 29 Desember 2016.

Sunjata,W.P., Tashadi, dan S.R.Astuti. 1993. Makna simbolik tumbuh-tumbuhan dan bangunan kraton. Departemen Pendidikan dan Kebudayaan, Direktorat Jenderal Kebudayaan, Direktorat Sejarah dan Nilai Tradisional Bagian Proyek Penelitian dan Pengkajian Kebudayaan Nusantara, Yogyakarta.

Viljoen, A., K. Bohn, dan J. Howe. 2005. Continuous Productive Urban Landscape: Designing Urban Agriculture for Sustainable Cities. Oxford. Architectural Press.

Yulianto, D. 2006. Persepsi kualitas estetika dan ekologi pada jalur wisata alam Taman Nasional Gede Pangrango. Program Studi Arsitektur Lanskap, Fakultas Pertanian. Institut Pertanian Bogor. 